\title{
Liquidation of solid particles of polydispersed grained material
}

\author{
Bakhronov Koshim Shayimovich ${ }^{1}$, Khudoiberdieva Nazora Sharofovna ${ }^{2}$, \\ Yunusova Sitora Tolib qizi ${ }^{3}$ \\ ${ }^{1}$ Navoi State Mining Institute Doctor of Technical Sciences, prof. Department of "Chemical technology". \\ E-mail: bahronav@mail.ru \\ ${ }^{2}$ Navoi State Mining Institute PhD, Assoc. Department of "Chemical technology". \\ E-mail: knazora@mail.ru \\ ${ }^{3}$ Navoi State Mining Institute student of the Department of Chemical Technology: \\ E-mail: sitora@mail.ru
}

\begin{abstract}
The results of experimental studies on the study of the expansion of the fluidized bed are presented. It is noted that the general picture of the expansion of the fluidized bed of polydisperse granular materials differs from monodisperse systems, and at the same time the porosity value of the pseudo-fluidized bed corresponds to the results of calculations according to the equations available in the literature.
\end{abstract}

Key words: Fluidized bed, polydisperse granular materials, fluidized bed, monodisperse systems, porosity, equations.

\section{INTRODUCTION}

One of the most promising methods for intensifying heat transfer is the use of a fluidized bed of solid granular material as an intermediate heat carrier. The main advantages of this method are: high values of heat transfer coefficients due to turbulization of the coolant flow by intensive mixing of the solid phase, a developed specific surface of the phase contact, the mobility of the suspended layer and the possibility of continuous circulation of the solid phase, a small hydraulic resistance of the fluidized bed, a relatively simple device design and the availability of their automation., as well as the possibility of using this method in operating devices.

The organization of fluidization of the polydisperse granular material of solid particles in the tubes of the heat exchanger eliminates the above disadvantages due to the destruction and turbulence of the near-wall layer of the liquid flow. However, the intensity of heat transfer from the surface to a liquid fluidized bed of a polydisperse granular material is practically not studied. There are no data in the literature on the influence of the size and concentration of particles, the physical properties of the granular material and the fluidizing liquid, as well as the parameters of the fixed and fluidized bed, such as the porosity and height of the bed, on the value of the heat transfer coefficient. In engineering practice, it is especially important to be able to estimate in advance the specific flow rate of liquid required to transfer particles of a granular layer of various diameters and densities into a fluidized state.

Recently, highly efficient tubular heat exchangers have been developed and successfully used in industry, in which a layer of granular material is used to intensify heat transfer and prevent scale deposition on the heat exchange surface, which is brought into a fluidized state during operation of the apparatus in an upward flow of the heat carrier. When using a fluidized bed as an intermediate heat transfer medium, a high degree of intensification can be achieved only when the heat exchange tube is completely filled with granular material. When calculating such devices, it is necessary to know the height of the suspended layer in the working, i.e., expanded state. The expansion of the bed is one of the most important characteristics of the state of a fluidized system; therefore, its study is necessary.

\section{MAIN PART}

Since it is almost impossible to control the height of the fluidized bed during the operation of heat exchangers, it is extremely important to know the dependence for calculating the height of the fluidized bed, taking into account all factors influencing it, for calculating and designing heat exchangers operating with a suspended bed.

It is known that the height of the fluidized bed is determined from the condition of equality of hydraulic resistances of the fixed and fluidized beds by the formula [1]:

$$
H=H_{0}\left(1-\varepsilon_{0}\right) /(1-\varepsilon)
$$


where $\mathrm{H}$ is the height of the fluidized bed; $\mathrm{H} 0$ is the height of the fixed layer of granular material; $\varepsilon 0$-porosity of the fixed layer of granular material; $\varepsilon$-porosity of the suspended layer.

An experimental study of the expansion of the fluidized bed was carried out on a laboratory bench in glass columns with a diameter of $20,22,36$, and $45.1 \mathrm{~mm}$. The range of change in the velocity of the fluidizing agent (water) in the apparatus was $0.0018-0.67 \mathrm{~m} / \mathrm{s}$, the initial static height of the granular material layer varied from 10 to $20 \mathrm{~cm}$. As a granular layer, particles of irregular shape were used: gravel, round glasses, lead and cation exchanger KU-2-8. The hydraulic resistance was determined by a direct method, i.e. the impulse tube was installed directly above the distribution grid under the granular material.

The average porosity of the fluidized bed was determined in a conventional manner. The rate of onset of fluidization remained unchanged for each fraction of particles and did not depend on the height of the fixed bed of granular material. The experimental values of this rate were in good agreement with those calculated by the Todes formula for all used fractions of granular material.

Visual observations of the expansion of the suspended bed showed that in narrow tubes (with a diameter of 20 and $22 \mathrm{~mm}$ ) and at heights of a fixed bed of more than $15 \mathrm{~cm}$, a piston fluidization mode is observed. When the granular material was fluidized with water in apparatus with diameters of 36 and $45.1 \mathrm{~mm}$, there was no piston formation, and the bed expanded more uniformly than when the same particles were fluidized in pipes with diameters of 20 and $22 \mathrm{~mm}$.

In the experiments carried out, the porosity of the suspended layer and the degree of its expansion Hd / H0 were also measured. Experimental data show (Fig. 1) that for all investigated particles the porosity of the layer in the entire interval of fluid velocities increases continuously and practically the same. Thus, it is proved once again that in the process under study, the state characteristic of fluidization at lower fluid velocities is not achieved, when the actual velocities in a wide range, changes in the fluid flow rate remain constant. The estimates show a continuous increase in the actual fluid velocity. These data also indicate that the nature of fluidization of heavy particles differs from fluidization of a layer of fine spherical particles.

\section{DISCUSSION}

The current values of the porosity of the fluidized bed in the full range of the fluidized state depend on the flow regime, characterized by the Reynolds criterion. Therefore, the experimental values of $\varepsilon$ calculated by formula (1) are presented as functions of the Reynolds number (Fig. 1). Each experimental point is the result of averaging data from at least three measurements.

Expansion of the bed of solid particles fluidized by water, in comparison with gas beds, all other things being equal, in this case, a lower expansion ratio of the bed is observed, which is expressed by a large slope of straight lines. In all experiments, a clear upper boundary of the layer, the absence of a tendency to aggregation, and the practical equality of the theoretically calculated and measured pressure drops in the layer, typical for fluidization by a dropping liquid, were noted.

Experimental data show that for all investigated particles, the porosity of the layer in the entire range of fluid velocities increases continuously and almost equally. The experimental points are located near straight lines, and practically have no kink. Thus, it is proved once again that in the process under study, the state characteristic of fluidization at lower liquid velocities is not achieved, when the actual velocities remain constant in a wide range of changes in the liquid flow rate. These data also indicate that the nature of the fluidization of heavy particles differs from the fluidization of a bed of fine spherical particles.

With the expansion of the layer of solid particles, fluidized by water, in comparison with gas layers, all other things being equal, a

being equal, a
is observed, the

a clear upper

a tendency to

of the

pressure drops

a dropping

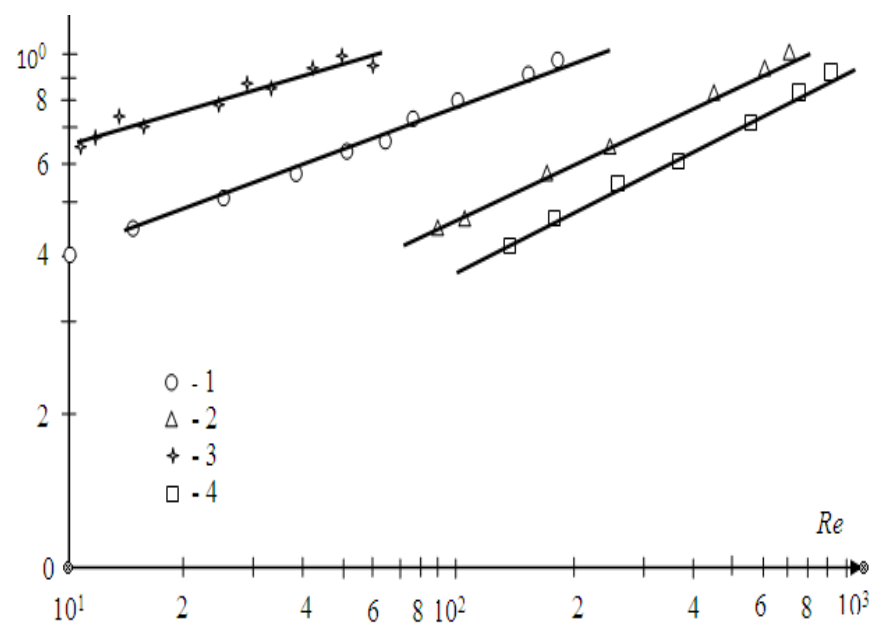

lower degree of expansion of the layer which is expressed by a large slope of experimental lines. In all experiments, boundary of the layer, the absence of aggregation, and the practical equality theoretically calculated and measured in the layer, typical of fluidization by liquid, were noted. 
Fig. 1. Dependence of the layer porosity on the Reynolds criterion: 1 - gravel particles, $\mathrm{d}=1.3 \mathrm{~mm}$; 2 - gravel particles, $\mathrm{d}$ $=3.04 \mathrm{~mm}$; 3-cation exchanger KU-2-8, $\mathrm{d}=0.84 \mathrm{~mm}$; 4-lead shot, $\mathrm{d}=1.84 \mathrm{~mm}$.

\section{CONCLUSION}

Expansion of a layer of solid particles fluidized with water was experimentally investigated. In all experiments, a clear upper boundary of the layer, the absence of a tendency to aggregation, and the practical equality of the theoretically calculated and measured pressure drops in the layer, typical of fluidization by a dropping liquid, were noted.

\section{LIST OF USED LITERATURE}

1. Aerov M.E., Todes O.M. Hydraulic and thermal foundations for the operation of devices with a stationary and fluidized granular bed. - L .: Chemistry, 1968 .-- 512 p.

2. Todes OM, Tsitovich OB Fluidized Bed Apparatus: Hydraulic and Thermal Basics of Operation. - L .: Chemistry, 1981 .-- 296 p.

3. Plastics Flammability Handbook. Principles, Regulations, Testing, and Approval. - 3rd ed. / Ed. by Jurgend Troitzsch. - Munich: Carl Hanser Verlag, 2004. - 718 p.

4. Fire retardancy of polymeric materials/ Ed. By A.F. Grand, C.A. Wilkie. - New York: Narsel Dekker, Inc., 2000. $-302 \mathrm{p}$.

5. Sanghyun Hong, Jaeho Yang, Sunghee Ahn, Yongik Mun, Gyucheol Lee. Flame retardant performance of various UL94 classified materials exposed to external ignition sources // Fire and Materials, 2004. - Vol. 28, Iss. 1, P. 25. - 3123. 24. Novel phosphorus\&modified polysulfone as a combined flame retardant and toughness modifier for epoxy resins / R.M. Perez, J.K.W. Sandler, V. Altstdt, et al. // Polymer, 2007. - Vol. 48. - Iss. 3. - P. 778-790.

6. Flame retardant synergism of rubber and $\mathrm{Mg}(\mathrm{OH}) 2$ in EVA composites / Gui H., Zhang X., Dong W. et al. // Polymer, 2007. - Vo. 48. - Iss. 9. - P. 2537-2541.

7. Li G., Liang G., He T., Yang Q., Song X. Effects of EG and MoSi 2 on thermal degradation of intumescent coating // Polymer Degradation and Stability, 2007. - Vol. 92. - Iss. 4. - P/ 569-579.

8. Study on preparation and fire\&retardant mechanism analysis of intumescent flame-retardant coatings / Gu J., Zhang G., Dong S., et al. // Surface and Coatings Technology2007. - Vol. 201. - Iss. 18. - P. 7835-7841.

9. Thermal stability and flame retardancy of LDPE/EVA blends filled with synthetic hydromagnesite/aluminium hydroxide/montmorillonite and magnesium hydroxide/aluminium hydroxide/montmorillonite mixtures. Haurie L., Fernandez A.I., Velasco J.I., et al. // Polymer Degradation and Stability, 2007. - Vol. 92. - Iss. 6. - P. 1082-1087. 